\section{Managing the Consequences of Neurosurgical Intervention in a Patient with Previously Undiagnosed Creutzfeldt- Jakob Disease}

To the Editor-We read with interest the experience of the Centers for Disease Control and Prevention in the management of neurosurgical instruments exposed to CreutzfeldtJakob disease (CJD) and the consequences thereof. ${ }^{1}$ They describe 19 incidents and discuss matters such as the interval from procedure to diagnosis, the tracing of instruments, and communication with the index patient and potential contacts. We recently experienced an incident involving a patient who was unexpectedly found to have CJD, which raised significant organizational and ethical issues that informed our management of the case.

An antemortem diagnosis of CJD was made in a patient who had undergone resective-disconnection neurosurgery 16 days earlier. The diagnosis was based on the presence of spongiform change in resected brain and was confirmed with immunohistochemical demonstration of proteinase K-resistant prion protein. A multidisciplinary incident management team was promptly established, which liaised with public health and expert advisory panels in Ireland and the United Kingdom using published guidelines. ${ }^{2,3}$ However, the application of those guidelines raised practical issues when determining what was best for the index patient and in calculating the number of contacts.

Belay et $\mathrm{al}^{1}$ describe a median time from the date of the index surgical procedure to the diagnosis of 10 weeks (1 day to 1 year), and although the interval in our case was at the lower end of this range, it still represented a significant delay. A number of patients were exposed to instruments used during the surgical procedure involving the index case patient. In our hospital, all neurosurgical packs are electronically traced, but individual items are not, and instruments used to treat a neurosurgical patient are washed and disinfected and subsequently sorted with other instruments (including nonneurosurgical instruments) before repacking and autoclaving. Consequently, a large patient population was exposed to a variety of instruments that posed varying risks of transmission. To have quarantined all of these instruments and limited neurosurgery in our hospital, which has ongoing emergency and scheduled-care responsibilities, would have resulted in risk to patients, because there was no ready source of suitable alternative instruments. A decision was made to include as "contacts" only those patients exposed to instruments in direct contact with the brain tissue of the index case patient. This resulted in a significant reduction in the potentially exposed population. The UK guidelines suggest that instruments that have been reused and processed 10 times or more are unlikely to pose significant risk. ${ }^{3}$ However, that is still likely to leave a significant number of patients who have been exposed to instruments that have been reprocessed less than 10 times.

Our approach to communication with the index patient, the contacts, and the public was a challenge in terms of being transparent while not causing undue anxiety and maintaining confidentiality. Once the diagnosis was confirmed and the information became available to the multidisciplinary incident team, a press statement was issued that generated considerable media attention. The index patient and family were counselled. A senior physician telephoned all potentially exposed patient contacts on the day after the statement, and all were offered the opportunity to meet a consultant neurologist and a clinical psychologist at their earliest convenience. Belay and colleagues suggest that there is "no overriding public health justification .... to mandate notification of potentially exposed patients." ${ }^{1(\mathrm{p} 1,278)}$ That is questionable, because these incidents raise considerable public concern, and levels of individual anxiety may be high. Although the relative risk to contacts may be very small, communicating that risk to the public and to exposed patients is, we believe, always ethically appropriate and the best approach to take, even if challenging. Anecdotally, the feedback from patients contacted was very positive, although numbers were small; the large number of patients who contacted the helpline illustrated the need for information from patients who had attended the hospital in the preceding weeks and months.

The best method to minimize such incidents is to identify in advance those patients with potential CJD, so that, if possible, disposable instruments are used and reusable instruments are quarantined until the diagnosis is excluded or destroyed if the patient is found to be CJD positive. However, there is no universally accepted and feasible screening tool. It is not possible to confirm a diagnosis of CJD in less than 2 days unless the diagnosis is suspected at the time of biopsy and arrangements made to perform Western blot for demonstration of protease-resistant prion protein on fresh brain tissue. In cases in which the possible diagnosis is suspected before surgery, instruments should be removed from circulation and quarantined while awaiting the result, and in cases in which a result is equivocal or unavailable, risk assessment should be undertaken. Using this approach, recirculation of instruments, as occurred in cases B, H, and Q of the series reported by Belay et al, ${ }^{1}$ would not have occurred. Since the incident, we have devised a simple questionnaire for no emergency neurosurgical patients with a view to reducing risk while acknowledging that many prion disorders have pro- 
longed preclinical latency, which makes it impossible to completely eliminate potential iatrogenic transmission.

A diagnosis of CJD may emerge unexpectedly, and a multidisciplinary approach is essential to ensure that the welfare of patient and contacts is managed optimally. Risk assessment, through the use of a screening tool for nonemergency patients, and the comprehensive tracking of all instruments used in surgical procedures is required, as is available in many sectors of the manufacturing industry. Finally, clear, honest, and appropriate communication with patients and contacts, although difficult, is essential, not least because such patients may have to undergo additional surgical or dental procedures, in which case their instruments must be identified, withdrawn, and incinerated and blood donation is contraindicated. Disclosure is in the best interests of patients and is more likely to minimize damage to institutional reputations.

\section{ACKNOWLEDGMENTS}

Potential conflicts of interest. All authors report no conflicts of interest relevant to this article. All authors submitted the ICMJE Form for Disclosure of Potential Conflicts of Interest, and the conflicts that the editors consider relevant to this article are disclosed here.

\section{Edmond G. Smyth, MSc, FRCPI, FRCPath; ${ }^{1,2}$ Michael Farrell, FRCPI, FRCPC, FRCPath; ${ }^{3}$ Daniel G. Healy, MB, PhD; ${ }^{4}$ Caoimhe Finn; ${ }^{5}$ David O'Brien, FRCS(SN); Donncha F. O'Brien, MD, FRCSI (SN); Rachel Howley, PhD; ${ }^{3}$ Patrick Turner, MSc; ${ }^{7}$ Hilary Humphreys, MD, FRCPI, FRCPath ${ }^{1,2}$}

Affiliations: 1. Department of Microbiology, Beaumont Hospital, Dublin, Ireland; 2. Department of Clinical Microbiology, Royal College of Surgeons in Ireland, Dublin, Ireland; 3. Department of Neuropathology, Beaumont Hospital, Dublin, Ireland; 4. Department of Neurology, Beaumont Hospital, Dublin, Ireland; 5. Department of Infection Prevention and Control, Beaumont Hospital, Dublin, Ireland; 6. Department of Neurosurgery, Beaumont Hospital, Dublin, Ireland; 7. Central Sterile Supplies Department, Beaumont Hospital, Dublin, Ireland.

Address correspondence to Edmond Smyth, MB, Msc, FRCPI, FRCPath, Department of Microbiology, Beaumont Hospital, Dublin 9, Ireland (edmondsmyth@beaumont.ie).

Infect Control Hosp Epidemiol 2014;35(7):908-909

(C) 2014 by The Society for Healthcare Epidemiology of America. All rights reserved. 0899-823X/2014/3507-0025\$15.00. DOI: 10.1086/676879

\section{REFERENCES}

1. Belay ED, Blase J, Sehulster LM, Maddox RA, Schonberger LB. Management of neurosurgical instruments and patients exposed to Creutzfeldt-Jakob Disease. Infect Control Hosp Epidemiol 2013; 34:1271-1280.

2. Scientific Advisory Committee of the Health Protection Surveillance Centre. Control and prevention of CJD and other transmissible spongiform encephalopathies (TSES) in Irish Healthcare settings. Dublin, Ireland: Healthcare Protection Surveillance Centre, 2011.
3. UK Department of Health. Management of possible exposure to CJD through Medical Procedures: framework document 2011. http://webarchive.nationalarchives.gov.uk/20060715141954/.

\section{Reply to Smyth et al}

To the Editor-We thank Smyth et $\mathrm{al}^{1}$ for their letter reporting a recent situation consistent with the incidents described in our article, ${ }^{2}$ wherein potential patient exposure to prioncontaminated instruments occurred after a surgical procedure involving an index patient who subsequently received a diagnosis of Creutzfeldt-Jakob disease (CJD). As indicated in our article, we agree that the best method to limit the occurrence of these scenarios is the advance identification of patients with potential CJD so that instruments may be managed appropriately. Use of a presurgery questionnaire, such as the one devised by Smyth et al, ${ }^{1}$ may be helpful in this regard.

Our experience with evaluating these incidents has reinforced our belief that the determination of whether to notify potentially exposed patients is not as straightforward as Smyth et $\mathrm{al}^{1}$ suggest, and a decision to notify may not always be in the best interests of the patients. In their own example, Smyth et $\mathrm{al}^{1}$ explain that contacts and, it follows, those patients who were notified were defined as only those patients exposed to instruments in direct contact with brain tissue from the index case patient. This determination was made on the basis of an assessment of transmission risk. Examples of other factors that may influence this risk and be informative in making notification decisions include (1) the certainty of the CJD diagnosis in the index patient, (2) the number of times that a contaminated instrument was routinely sterilized before the potential exposure event, (3) the likelihood that the same neurological instrument set was used to treat the index patient and potentially exposed patients, and (4) the prognosis of the potentially exposed patients due to the underlying conditions that necessitated their procedures. To be clear, the above comments are not made to advocate either for or against notification of patients. Rather, they underscore that, because the variables and known facts of each incident vary, experts may differ in their opinion of whether notification is the ethically appropriate choice. ${ }^{3}$ These decisions, given their potential effects, should not be made lightly.

\section{ACKNOWLEDGMENTS}

Potential conflicts of interest. All authors report no conflicts of interest relevant to this article. All authors submitted the ICMJE Form for Disclosure of Potential Conflicts of Interest, and the conflicts that the editors consider relevant to this article are disclosed here.

Ryan A. Maddox, $\mathrm{PhD} ;{ }^{1}$ Lawrence B. Schonberger, $\mathrm{MD} ;{ }^{1}$ 